\title{
Constant voltage constant current power supply control system for Single-chip design
}

\author{
Quan Zhou ${ }^{1, a}$, Yonghui Xie ${ }^{2, b}$ \\ ${ }^{1}$ Electrical engineering, No. 243 Dongfeng East Street, Weifang City, Shandong Province, China \\ ${ }^{2}$ Electrical engineering, No. 243 Dongfeng East Street, Weifang City, Shandong Province, China \\ a kyd1981cn@163.com, byhfdzh@tom.com
}

Keywords: D / A conversion; Regulators Power; V / I

\begin{abstract}
As electronic technology to the continued progress of the requirements of electronic devices is also rising. Power circuit as a source of motive is playing an increasingly important role, Regulators sources in various laboratories or other places are indispensable. SCM technology with the continuous development and D / A and A / D technology continues to mature NC Power makes it possible, Digital control technology becomes more and more popular in the field of power supplies. NC current source is in control regardless of the accuracy or operability have the traditional power unmatched advantages.
\end{abstract}

\section{Foreword}

Regulators sources in various laboratories or other places are indispensable, Traditional AC stabilized voltage supply is basically belong to dissipation ofenergy. It's theory is using nonlinear device such as voltage regulator tube or ferroresonance steady voltage transformer assisted with necessary circuit to realize the autoregulation of output voltage. It's ciruit is mature and theory is consummate. But thiskind of supply has some idiopathic shortage.For example, supply using magnetismsaturation has the following shortage: size is big, weight is heavy; cost is high, efficiency is low, self-consuming is high; high ripple coefficient of output voltage and low stabilization and efficiency.

SCM technology with the continuous development and D / A and A / D technology continues to mature NC Power makes it possible. Compared with analog controllers, digital controllers have many advantages. The digital controller can realize some complicated control strategies and has higher reliability and stability, and the design of the digital controller is flexible. The digital controller can realize the intelligent power and reduce the design cycle of new products.

The subject in the current traditional reference sources, and ordinary NC current source, on the basis of fully considering the cost performance while greatly enhancing the NC accuracy of the current source, the power supply can be constant voltage and constant current output, Press through its output voltage / flow control value stepper. Output voltage value using Digital Display 3.

Some figures with 51 microcontroller as a core control. Through D / A converter module to control the output voltage, while Sampling through sampling circuit output voltage / current and feedback to the microcontroller. in order to enable voltage / current output more stable.

The design of the main SCM control and display module, D/A conversion module, constant current source module, output display module and feedback module. SCM control module using SCM as the core, convert the input current signal into digital output; the constant current source module D/A conversion to analog voltage through a constant current source circuit into a constant current; the display module to display the current or voltage; The feedback module is the output voltage and current sampling, through the A/D conversion after the feedback to the microcontroller and compared to a predetermined, and adjust its output, the output is more stable. 


\section{Power Supply Module}

Power modules make use of linear current source programs in the design, and add the active filter circuit.

Power transformer: A $150 \mathrm{~W}$ dual $18 \mathrm{~V}$ single 9V, 26V ring step-down transformer will change $220 \mathrm{~V}$ AC grid transform into about $25 \mathrm{~V}$ AC power, the main and vice coil turns than about 9: 1 . After the rectification of AC voltage will be required DC voltage by electronic equipment.

Rectifier circuit: the use of single-phase bridge rectifier circuit to change the direction and size of the $50 \mathrm{~Hz}$ AC is transformed into the DC which is the same direction but still the pulse size. The advantage is the higher voltage, a smaller ripple voltage, rectifier diodes subjected to the maximum reverse AC current flow, the high utilization of the transformer.

Filter circuit: the use of the nature of mutations of energy storage components - capacitor $\mathrm{C}$ at both ends of the voltage, That RC filter circuit filte out most of the pulsation components of the output of rectifier circuit, has been relatively smooth DC. Using $4700 \mathrm{uF}, 50 \mathrm{~V}$ capacitor filter to achieve a better filtering effect.

Regulator circuit: After the 7815791578057905 regulator rectifier filter circuit so that the DC voltage does not communicate with the grid and load changes and changes in the disturbance. Power Supply Module is shown in Fig. 1.

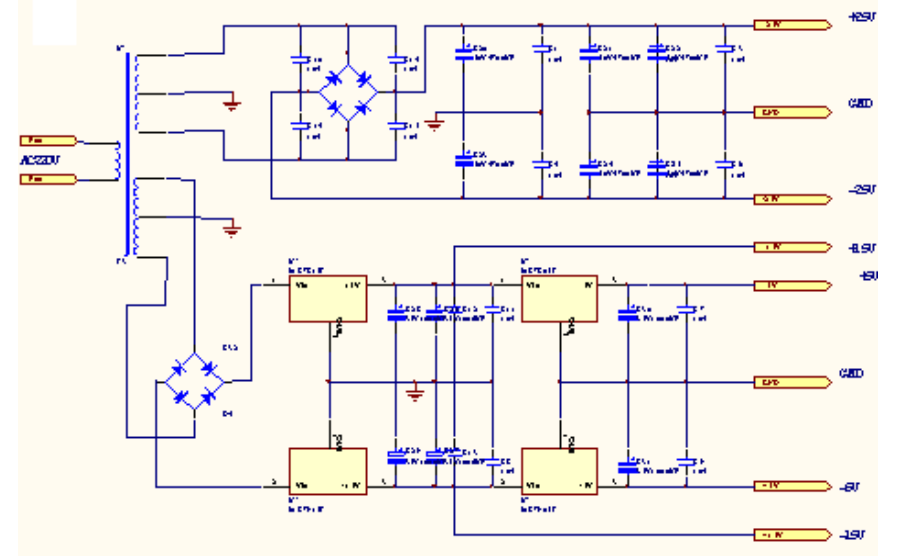

Fig. 1 System Diagram power

\section{The System Display Module}

System display module using three semi-double integral ICL7107, analog voltage can be directly converted into BCD code, drive LED display, the display range is $0 \sim 19.99 \mathrm{~V}$, the minimum resolution is $10 \mathrm{mv}$, to meet the circuit design requirements.

74LS595 is the serial input and parallel output shift register, can be used as a static display interface, and then the serial port in the 89C52 used for digital display. Digital display module as shown in Fig. 2.

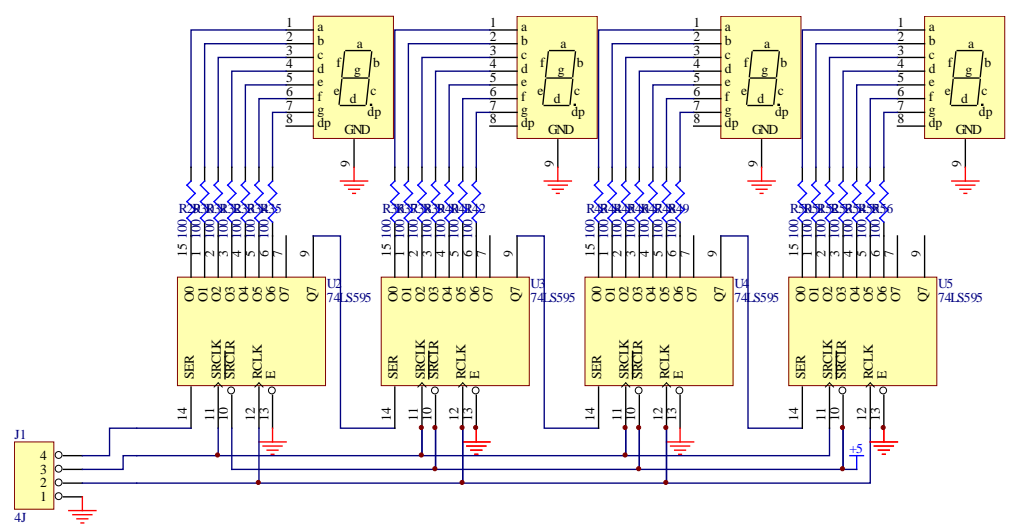

Fig. 2 Digital display module diagram 


\section{D / A circuit}

As a result of the coarse sub-harmonic control the accuracy of fine-tune system voltage / current output greatly improves, to cost and component procurement consider, using DAC0832 circuit as a D / A conversion circuit.

DAC0832 is an 8-bit D / A converter chip, single power supply, from the $+5 \mathrm{~V} \sim+15 \mathrm{~V}$ may be the normal work, the reference voltage range is $\pm 10 \mathrm{~V}$, time current set up is $1 \mu \mathrm{s}, \mathrm{CMOS}$ technology, low power consumption 20mA. Its internal structure as shown, which is made of an 8-bit input registers, an 8-bit DAC registers and an 8-bit D / A converters, the pin ranges as shown in Fig. 3.

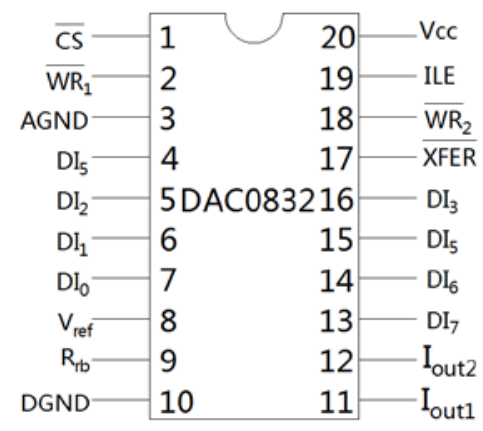

Fig. 3 DAC0832 pin map

\section{V / I conversion circuit}

The using of output type D / A converter can achieves to current output, but its output current in $\mu \mathrm{A}$ the amplitude of the general order of magnitude, so the need for a number of times the current amplification to achieve the required current value, the circuit is very difficult to achieve. So we choose voltage output type DAC, then transform into a VI conversion circuit in proportion with the current signal, the circuit is relatively easy to achieve in this program, V / I conversion circuit design is the key. Through the analysis we have chosen total load by way of V / I conversion circuit. V / I conversion circuit as shown in Fig. 4.

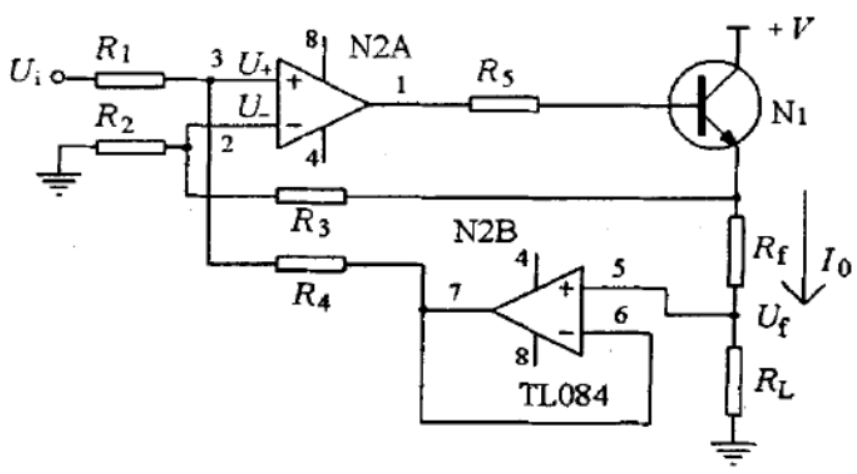

Fig. 4 Ways to load a total of V / I Conversion Circuit

\section{Filter module}

Simple RC filter circuit or $\pi$-type RC filter circuit can not meet the design requirements, so I choose to set up a new transistor devices in the $\pi$-type RC active filter circuit, and to the composition of the active RC filter circuit. Filter module as shown in Fig. 5. 


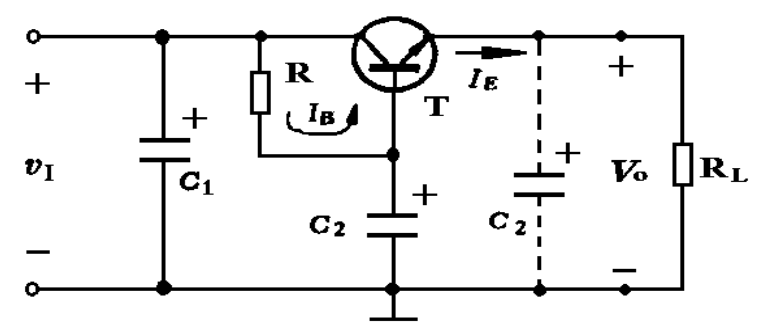

Fig. 5 Active filter circuit

\section{Power amplifier output}

According to the design requirements we have chosen three LM337/LM317 client which is adjustable voltage regulator IC, and its output voltage range is $1.2 \mathrm{~V}$ to $37 \mathrm{~V}$, load current is up to $1.5 \mathrm{~A}$. Its use is very simple, only two external resistors to set the output voltage. In addition, its the adjust rate of linear and the adjust rate of load are better than standard fixed regulators. LM337/LM317 have built-in overload protection, security protection and other protection circuit.

\section{Sampling feedback module}

Sampling feedback circuit has two input sample value, the output voltage signal sample taken at the output of parallel resistors, by the method of partial pressure resistor voltage attenuation, the output current signal sample is in the main loop through the sampling resistor in series that will load current into a voltage signal sent to A / D conversion unit realized. Sampling feedback circuit diagram as shown in Fig. 6.

After sampling the signal to the ADC0809 ADC, the analog signal is converted to digital signals, in comparison to the single-chip microcomputer, ADC0809 are with 8 A / D converter, 8-way multi-way switch as well as micro-processing machine-compatible CMOS control logic components. Internal structure as shown, which is component of 8-channel analog switch, the address latch and decoder, comparator, 8 switch tree $\mathrm{D} / \mathrm{A}$ converters, successive approximation register and a three-state output latch. ADC 0809 internal structure map as shown in Fig.7.

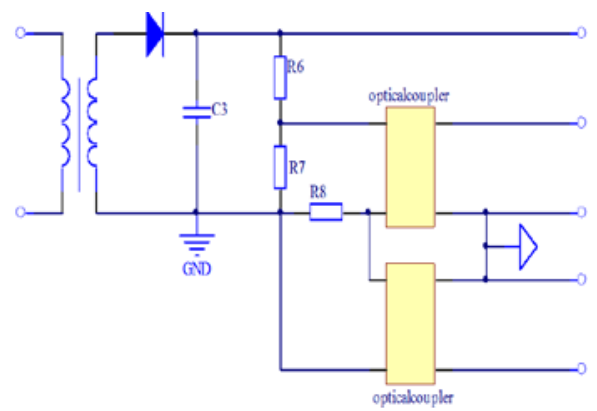

Fig. 6 Sampling feedback circuit

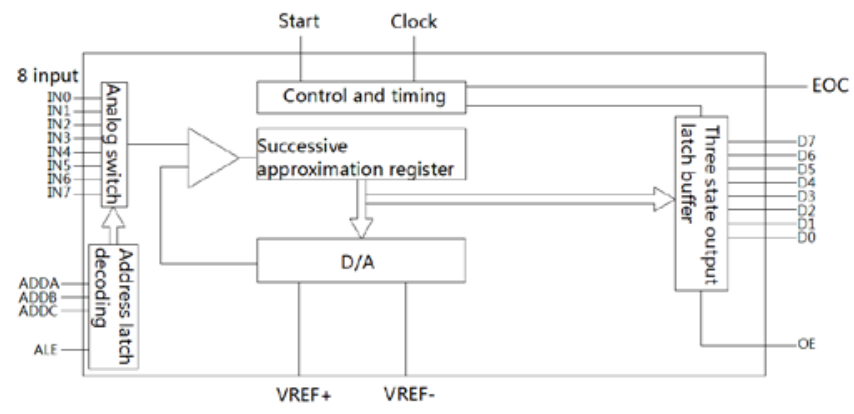

Fig. 7 ADC 0809 internal structure map

\section{The keyboard module}

Keyboard module for computer systems usually have two kinds of keyboard: one category is coded keyboard, and the other non-coding keyboard ,here I would like to choose a non-coding keyboard 3x3 structure, which can automatically eliminate the impact of key jitter, has protection to the key on the button and pressed at the same time, can the keyboard into the stack information, can also be issued to the CPU interrupt request, after the response, so that CPU access to key information, it is still acceptable CPU inter-team information inquiries. 


\section{AT89C52 single-chip microcomputer systems and peripheral circuits}

In circuit design I chose the most common ATMEL Corporation AT89C52 single-chip microcomputer. This single-chip microcomputer with the MCS-51 instruction set is fully compatible with products from $8 \mathrm{~K}$ bytes Flash re-write flash memory, $256 \times 8$ bytes of internal RAM, 32 programmable I / O port line, 216 timer / counter and 6 interrupt sources. And single-chip microcomputer is economical and practical, widely used, its main parts of the circuit as shown in Fig.8:

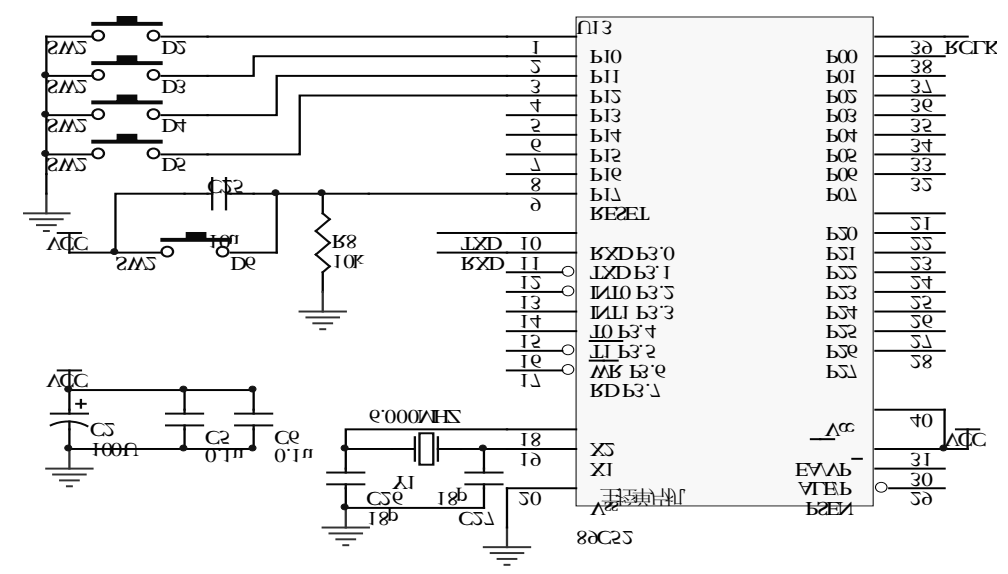

Fig. 8 The control circuit diagram

This design through the MCU as the core to control, plus a number of peripheral circuits by controlling the D / A converter input to change the final output, to achieve the purpose of NC. As mentioned above, the NC power supply has many obvious advantages, such as output in a certain range for, as a signal source to be able to output, through software changes to achieve many of the features, without the need to change the number of hardware circuit wiring. Finally, by the test of ultimate system performance, design has proven that system output is with high accuracy, and can achieve the desired objective.

\section{References}

[1] J.Sun and H.Grotstollen.Symbolic analysis methods for averaged modeling of switching power converters[J].IEEE Transactions on Power Electronics,1997,12(3):537-546.

[2] Lin Bor-Ren,@Hua Chihchiang,Hua Chihchiang.Uninterruptible Power Supply With Fuzzy Logic Approach.Industrial Electronics,Control,and Instrumentation, 1993. Proceedings of the IECON '93.International Conference on.vol. 2:1123 1128.

[3] Dixon.L.H.Average current Mode Control of Switching Power Supplies.Unitrode Power Supply Design Semi-nar Manual SEM700.1990.

[4] C.Deisch.Simple switching control method changes power converter into a current source[C].Proc.IEEE Power Electronics Specialists Conf.1978,:300 306.

[5] Daniel MMitchell.An Analytical Investigation of Current-Injected Control for Constant-Frequency Switching Regulators[J].IEEE Transactions on Power Electronics,1986,(7): 167-174.

[6] Robert Mammano.Switching Power Supply Topology Voltage Mode vs. Current Mode. Unitrode Product \& Applications Handbook.1995-96.

[7] Lloyd Dixon.Average Current Mode Control of Switching Power Supply. Unitrode Product \& Applications Handbook.:1995-96. 